\title{
Broad Band Microstrip Patch Antenna Based on Foam-Filled and One Open Slot on Backward of Radiating Layer
}

\author{
Ali Esseid Almuzwghi, Lail Brian \\ Department of Computer Engineering and Science, Florida Institute of Technology, Melbourne, FL, USA \\ Email: esseid2014@gmail.com
}

How to cite this paper: Almuzwghi, A.E. and Brian, L. (2019) Broad Band Microstrip Patch Antenna Based on Foam-Filled and One Open Slot on Backward of Radiating Layer. Journal of Computer and Communications, 7, 15-28.

https://doi.org/10.4236/jcc.2019.76003

Received: April 14, 2019

Accepted: June 27, 2019

Published: June 30, 2019

Copyright ( 2019 by author(s) and Scientific Research Publishing Inc. This work is licensed under the Creative Commons Attribution International License (CC BY 4.0).

http://creativecommons.org/licenses/by/4.0/

(c) (i) Open Access

\begin{abstract}
A broadband microstrip patch antenna, loaded E-U-shaped open slot on backward of radiating layer is proposed and experimentally investigated. The antenna employs a foam-filled dielectric substrate, whose dielectric constant is within the lower end of the range. The proposed antenna has been designed for electromagnetic analysis including the impedance bandwidth, reflection coefficient, radiation pattern, and antenna gain. The open slot is loaded on the back radiated layer, which is perpendicular to the radiating edge of the oblong microstrip patch component, where the symmetric line feed is selected. This new technique used to increase the bandwidth and the gain of antenna through increasing current path by slot location, width and length on backward of radiating Layer. The main structure in this research was a single microstrip patch antenna planar with three layers operating at two resonant frequencies $4.440 \mathrm{GHz}$ and $5.833 \mathrm{GHz}$. All the simulated results are confirmed by two packages of electromagnetism simulation. An impedance bandwidth ( $\mathrm{S} 11 \leq-10 \mathrm{~dB}$ ) up to about $41.03 \%$ and $30.61 \%$ is achieved by individually optimizing its parameters. The antenna exhibits nearly stable radiation pattern with a maximum gains of $8.789 \mathrm{dBi}$ and $9.966 \mathrm{dBi}$, which is suitable for Wi-Fi Band, satellite communications, and wireless presented. Whereas the results before this design that we have a proof of publication are $36.17 \%$ and $28.43 \%$.
\end{abstract}

\section{Keywords}

Broad Band, Foam, One Open Slot, Three Layers, Two Packages, Electromagnetism Simulation

\section{Introduction}

With a booming period and desire in modern wireless communication applications, microstrip patch antennas have attracted much interest due to their com- 
patibility with printed circuits without problems, light weight, profile, and ease of fabrication [1] [2] [3] [4]. A major challenge of microstrip patch antenna design comprises its commercialization that requires wide impedance bandwidth, high efficiency and high gain along with taking care at a low price in a single design. For over a period two decades, investigators and scientists have developed several methods to increase the impedance bandwidth, high efficiency and high gain of patch antenna. One of that methods, the impedance bandwidth of the microstrip patch antenna, increases with a decrease in the relative permittivity dielectric constant ( $€ r)$ [5] [6] [7] or with an increase in the layer thickness (h) [7] [8] [9] [10]. However, there is an experiential limit on increasing the layer thickness (h), while if increased beyond 0.1 wavelength $(\lambda 0)$, surface-wave propagation comes out, resulting in degradation in antenna performance. The bandwidth larger than $25 \%$ is accomplished utilizing gap-coupled coplanar microstrip resonators [10]. Another conventional broad-banding technique includes the use and inserting relatively thick air-gap [11] or foam-gap substrate [12], and in addition, organizing a two or more patches antenna on different layers of the dielectric substrates in one pile (stacked) [13] to achieve wide bandwidth.

In recent years, many designs have been reported to achieve wideband patch antenna for modern wireless communication devices. That includes use of various formed slot, slit and patch like U-shape slot antenna [14] [15] [16] [17] [18], wide band E-shape patch antenna [19] [20]. However, their realizable bandwidths of these designs are below $30 \%$. As example on that, covered dielectric layer which is separated from feed patch by air as another dielectric [21], an impedance bandwidth of $220 \mathrm{MHz}$, is achieved and gain is found as $13.4 \mathrm{dBi}$. The structure in this design is 2 by 2 microstrip patch planar array antenna using air substrate with $(€ \mathrm{r}=1)$ at frequency $5.8 \mathrm{GHz}$ [22]. The results show that the gain increases up to $14.63 \mathrm{dBi}$ if using air substrate compared to FR-4 substrate (9.04 $\mathrm{dBi}$ ). In another novel antenna structure which contains five substrate layers [23], the eight-element antenna array with feeding network achieved frequency band from 5.28 to $6.05 \mathrm{GHz} 15.4 \%$ and antenna gain of $16.24 \mathrm{dBi}$. Most of the reported papers in the literature are more complexes, high-cost, and have achieved a maximum bandwidth of $30 \%$ with gain below $16.24 \mathrm{dBi}$. The proposed design is low-cost and very simple with a single patch. It has achieved gain of $8.789 \mathrm{dBi}$ and $9.966 \mathrm{dBi}$ at a resonant frequency of $4.450 \mathrm{GHz}$ and $5.833 \mathrm{GHz}$ with directivity of $9.782 \mathrm{dBi}$ and $10.262 \mathrm{dBi}$ and a bandwidth of $41.03 \%$ and $30.61 \%$ respectively.

In our design, the results are accomplished by a little change in the distance between the top of the printed figure (open slot) and the end edge of the patch antenna while keeping the gap of the foam layer thickness constant. This modification provided relatively greater bandwidth with perfect radiation, higher efficiency, and higher gain. In general, this technique slot location and slot width and length with foam gap cause the increase in inductance on the current path of the signal. This should increase the bandwidth of the antenna as well as the efficiency and gain. 


\section{Antenna Design}

The one that is most recommendable for good reception apparatus execution are thick substrates, whose dielectric steady is in the lower value enclosed to 1 since they give better they provide better efficiency, produce high gain, and increase wide band. In this paper the impedance band and the gain proposed has been improved using foam substrate where dielectric constant $€ \mathrm{r}=1.03$ has thickness $3.2 \mathrm{~mm}$.

The first design, the foam substrate is inserted between the radiation layer and ground plane. The radiation layer used the Rogers_RT_Duroid5881 substrate with thickness $1.6 \mathrm{~mm}$ and permittivity $(\mathrm{Er})=2.17$ when the tangent loss is 0.0009 at top layer, whereas, the ground layer used the Rogers_RT_Duroid5870 substrate with thickness $1.6 \mathrm{~mm}$ and permittivity $(\mathrm{Er})=2.33$ when the tangent loss is 0.0012 at the bottom layer as shown in Figure 1.

The second design inserted driven layer (printed figure) between the radiating layer and foam gap. The driven layer is E-shaped or U-shaped. The dimensions of the patch antenna and driven layer are shown in Figure 2 and Table 1 . This technique making multilayer microstrip antenna has ability obtained enhanced bandwidth, enhanced gain of antenna, and better efficiency. In addition, the feed line used to feed the antenna. Microstrip line feed structure is more suitable if compared to Coaxial feed, due to no difficulty of fabrication, compatibility with printed circuits without problems and lower costs. Finally, the idea of this paper is to present the simulation results of our study of the antenna parameters under conditions, by means of an adjustable the distance between the top printed figure and the end edge of the point feed (D-L) and printed-figure style.

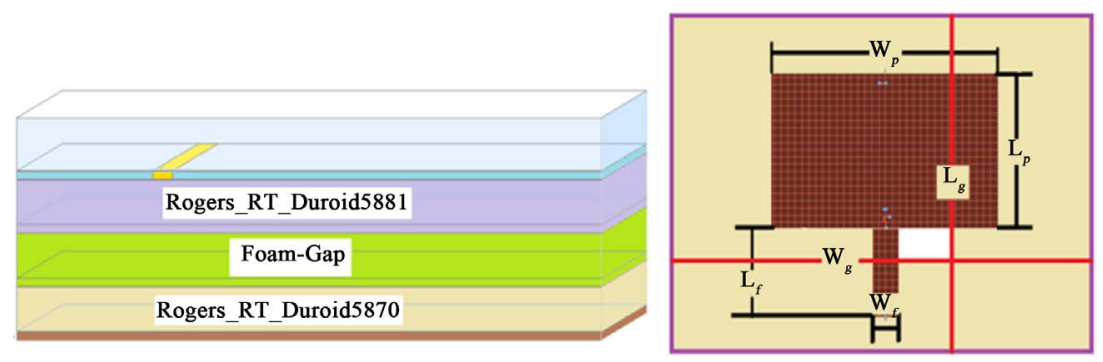

Figure 1. Design of the proposed antenna.
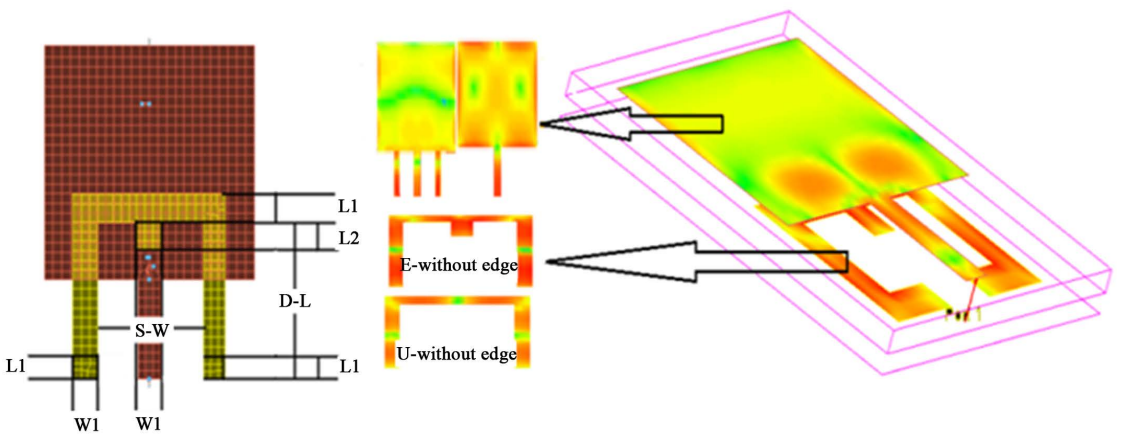

Figure 2. Design of the proposed antenna with driven layer E-U shaped. 
Table 1. Optimized values of proposed patch antenna parameters.

\begin{tabular}{cc}
\hline Parameters & Numerical Values in $\mathbf{~ m m}$ \\
\hline Ground Plane width $=W \mathrm{~g}$ & 80 \\
Ground Plane length $=$ Lg & 80 \\
Patch width $=W \mathrm{p}$ & 62.5 \\
Patch length $=L \mathrm{p}$ & 41.5 \\
Feeding width $=W \mathrm{f}$ & 3.0 \\
Feeding length $=$ Lf & 22.5 \\
Substrate height (Foam Gap) & 3.2 \\
Substrate height 1 \& 2 & 1.60 \\
D-L & $28.8-38.8$ \\
S-W & 41.6 \\
W1 & 5.5 \\
L1 & 5.5 \\
L2 & $7-3$ \\
\hline
\end{tabular}

\section{Optimized Antenna Design}

The sizes of the metallic antenna were slightly changed in order to enhance the antenna performance parameters. It is optimized from $28.8 \mathrm{~mm}$ to $38.2 \mathrm{~mm}$ in $1.0 \mathrm{~mm}$ increments, where the other parameters are constant. Finally, the total area of the ground plane is $80 \mathrm{~mm} \times 80 \mathrm{~mm}$ and the total area of the patch antenna is $62.5 \mathrm{~mm} \times 41.5 \mathrm{~mm}$.

\section{Results and Discussion}

\subsection{Antenna Design without Printed Figure and Foam Gap}

Microwave office (AWR) version 2018 and Advance Design System (ADS) version 2016 were used, whereas MATLAB used to compare the simulation results. All the results are displayed graphically and numerically, where the simulators have been utilized to acquire these outcomes. The main purpose of different algorithms simulation are to support objective decision making by means of results analysis, to enable design to safely plan their operations, and to compare favorably with present different algorithms. The results simulated a successfully to operate at specified frequencies are perfect agreement between different algorithms simulation.

\subsubsection{Simulation Results of Patch without Foam Gap and Driven Layer} The simulated plot of reflection coefficient ( $\mathrm{S} 11 \leq-10 \mathrm{~dB}$ ) against frequency is shown in Figure 3. Four return losses of (RL-1)-12.626 dB at $4.433 \mathrm{GHz}$, (RL-2)-19.43 dB at $5.833 \mathrm{GHz}$, (RL-3)-35.42 dB at $6.442 \mathrm{GHz}$, and (RL-4)-19.23 $\mathrm{dB}$ at $6.662 \mathrm{GHz}$ was obtained by $\mathrm{AWR}$, whereas, the return losses are (RL-1)-15.29 dB at $4.443 \mathrm{GHz},(\mathrm{RL}-2)-10.65 \mathrm{~dB}$ at $5.833 \mathrm{GHz},(\mathrm{RL}-3)-27.52 \mathrm{~dB}$ at 
6.438 GHz, and (RL-4)-15.57 dB at $6.662 \mathrm{GHz}$ was obtained by ADS. The corresponding impedance bandwidths are (BW-1) $0.066 \mathrm{GHz},(\mathrm{BW}-2) 0.065 \mathrm{GHz}$, (BW-3) $0.055 \mathrm{GHz}$, and (BW-4) $0.079 \mathrm{GHz}$. That is clear sure, the reflection coefficients and the resonant frequencies show better agreement between two software simulations. Both results prove that the antenna has good performance both. The small discrepancies between two simulated results could be attributed, because the two software's have the different logarithmic (Table 2).

\subsubsection{Simulation Results of Patch with Foam Gap and without Driven Layer}

Simulated results of microstrip patch antenna show the effect the thickness of foam gap in Figure 4 , which have $-40.46 \mathrm{~dB}$ and $-35.37 \mathrm{~dB}$ return losses with increased bandwidth up to $1.589 \mathrm{GHz}$ at $4.423 \mathrm{GHz}$ and $5.634 \mathrm{GHz}$ frequencies, which are 35.91 and 28.23 percent more than single patch antenna without gap.

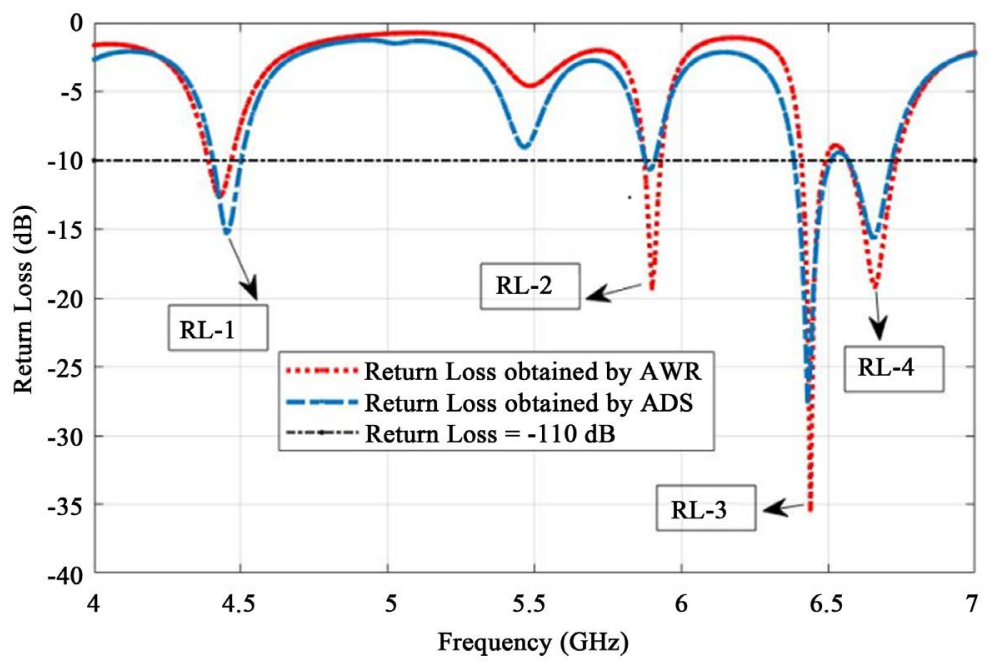

Figure 3. Return loss obtained by AWR and ADS of antenna without Gap and driven layer.

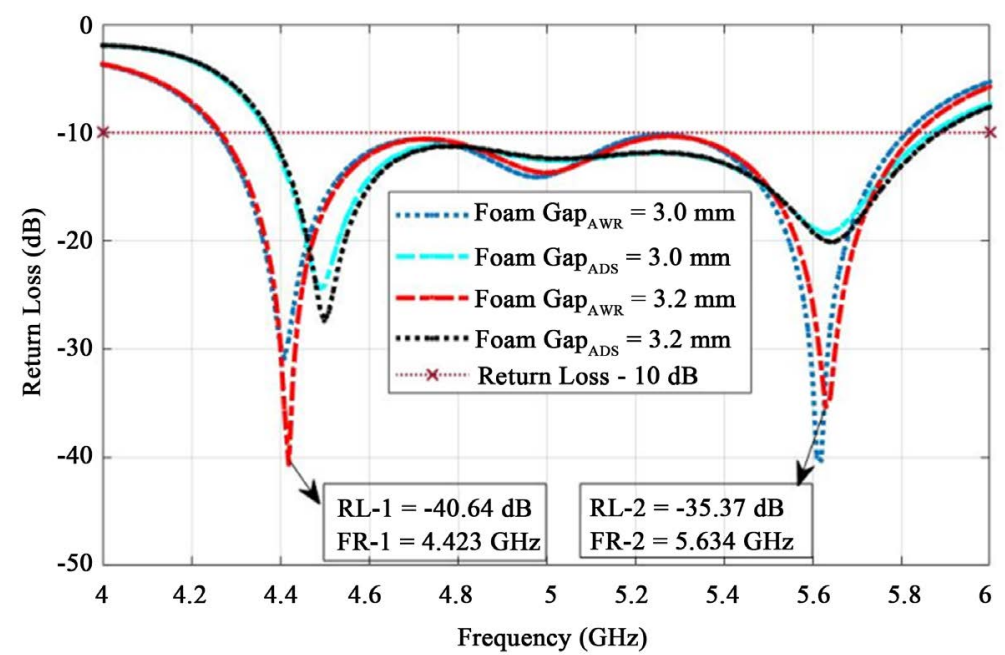

Figure 4. Return loss of microstrip patch antenna with foam gap. 
Table 2. Summary of simulated results of design an antenna without gap and slot.

\begin{tabular}{ccccc}
\hline Parameters & FR-1 & FR-2 & FR-3 & FR-4 \\
\hline Resonant Frequency in GHz & 4.430 & 5.90 & 6.440 & 6.660 \\
Return Loss in dB & -12.65 & -19.30 & -35.40 & -19.23 \\
Bandwidth in GHz & 0.066 & 0.065 & 0.055 & 0.079 \\
VSWR & 1.610 & 1.241 & 1.033 & 1.242 \\
Gain in dBi & 8.289 & 8.889 & 9.289 & 9.430 \\
Directivity in dBi & 9.620 & 9.720 & 9.920 & 10.748 \\
\hline
\end{tabular}

\subsubsection{Simulation Results of Patch with Foam Gap and Driven Layer} In order to fully understand the influence of the space between the top of printed figure and the edge of feed the patch (D-L) parameter, the parametric investigation was carried out by varying this parameter, while holding still existing parameters values as Section 2. This simulation was conducted using two different designs.

\subsection{Antenna Design with Printed Figure}

\subsubsection{The Effect of Print Figure E Shape on Power Reflection Coefficient and Resonance Frequency}

Figure 5(a) shows the parametric effect (D-L) on the reflection coefficient (S11 $\leq-10 \mathrm{~dB}$ ), and resonant frequencies when (D-L) parameter are varied.

The following section in Figure 5(b) shows the effect of a variable parameter (D-L), with the increase in the (D-L), the resonant frequency (FR-2) curve shifts towards lower resonant frequencies, while there is no significant change in the resonant frequency (FR-1).

AS the D-L smoothly increased, there are more amount to the fringing effects occurred, this leads to a better return loss (RL-1), whereas return loss (RL-2) has a maximum amount at $\mathrm{D}-\mathrm{L}$ is equal $34 \mathrm{~mm}$, after that, it turn into inverse direction as shown in Figure 5(c).

\subsubsection{Bandwidth by Taking the (D-L) as a Parameter for Patch Antenna}

The distance (D-L), is varying from $28.0 \mathrm{~mm}$ to $29.0 \mathrm{~mm}$, there is very little variation in the absolute value of the bandwidth (BW-1) and the bandwidth (BW-2). The bandwidth (BW-1) and the bandwidth (BW-2) have a rapid increase to the maximum value where the distance (D-L) has an increase from 29.0 $\mathrm{mm}$ to $30.0 \mathrm{~mm}$, whereas the distance $30.0 \mathrm{~mm}$ to $38.0 \mathrm{~mm}$ all bandwidths are a slowly decrease as shown the result in Figure 6. A significant bandwidth is observed at distance of the printed figure beyond at $30.0 \mathrm{~mm}$, it is appreciable extent. In these points of observation, the bandwidths are close to $1.821 \mathrm{GHz}$ or $41.03 \%$ and $30.61 \%$.

\subsubsection{Gains and Directivities by Taking the (D-L) as a Parameter for Patch Antenna}

Figure 7 shows directivities and gains Vs distance (D-L). All directivities are slowly increasing from $28.0 \mathrm{~mm}$ to $35.0 \mathrm{~mm}$, whereas the distance at $35.0 \mathrm{~mm}$ to 


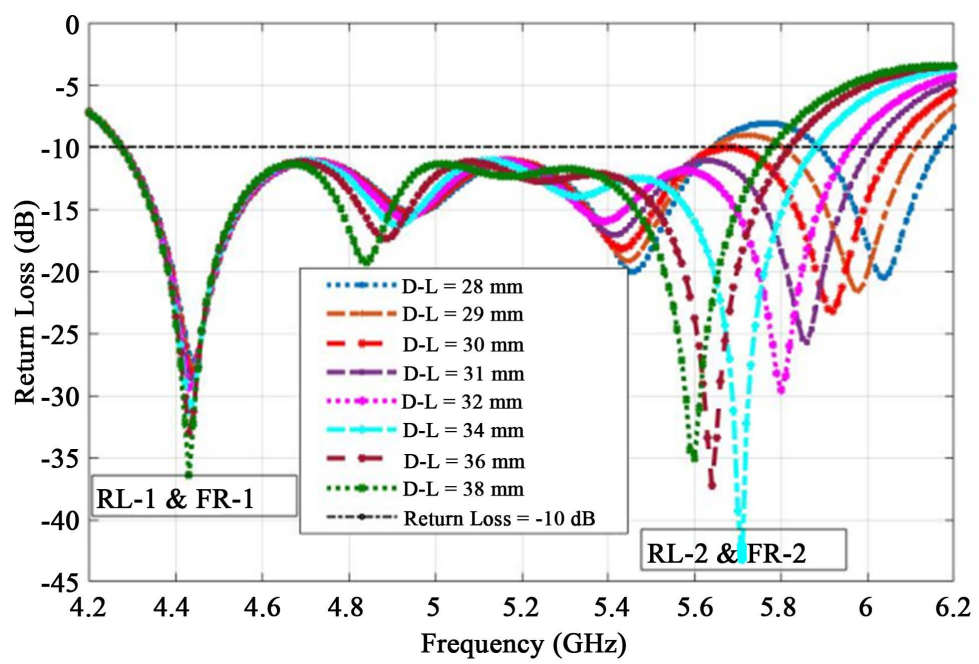

(a)

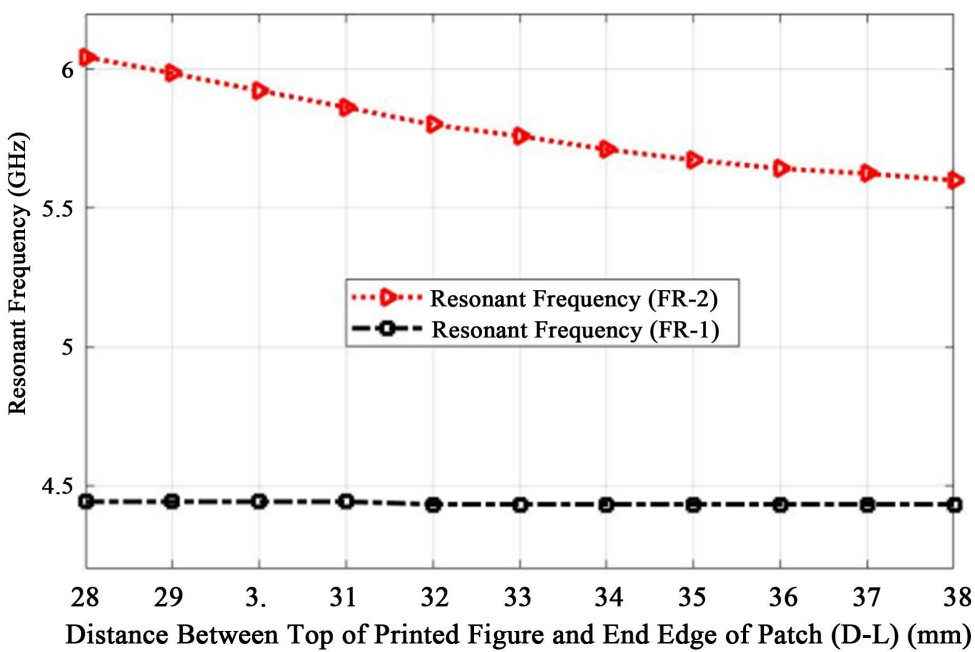

(b)

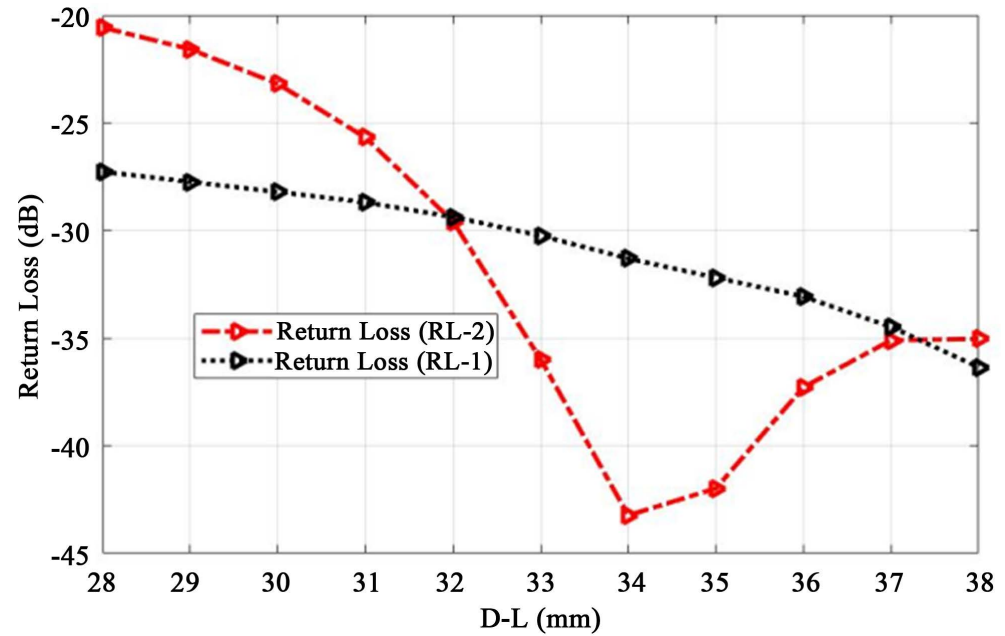

(c)

Figure 5. (a) Power reflection coefficient (S11) and resonance frequency different values of (D-L); (b) Resonance frequency for figure E shape at different values of (D-L); (c) Power reflection coefficient (S11) for figure E shape at different values of (D-L). 


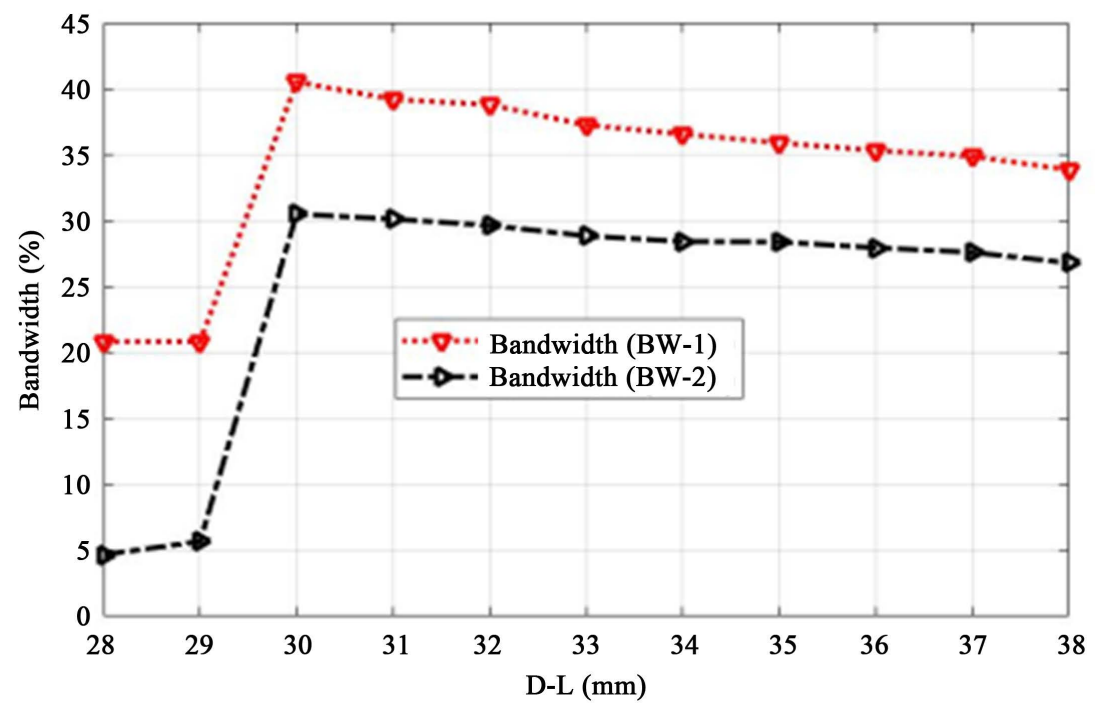

Figure 6. Bandwidth for figure E shape at different values of (D-L).

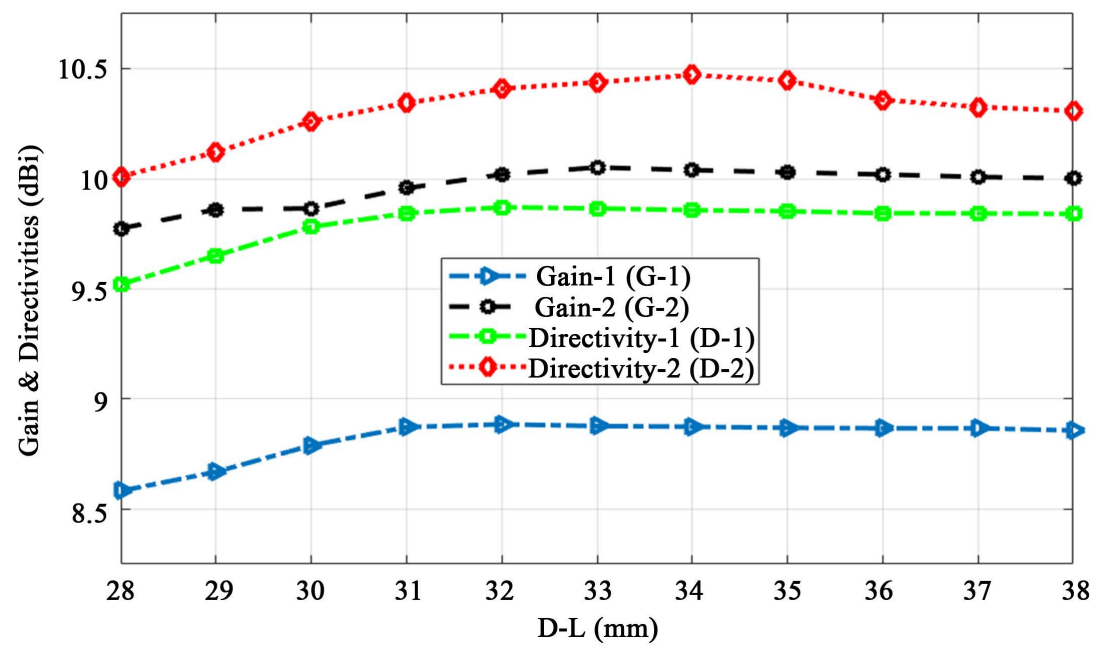

Figure 7. Gains and directivities for different values of (D-L).

$38.0 \mathrm{~mm}$ directivities are a slowly decrease. However, gains are slowly increasing from $28.0 \mathrm{~mm}$ to $34.0 \mathrm{~mm}$, whereas the distance at $34.0 \mathrm{~mm}$ to $38.0 \mathrm{~mm}$ gains are a slowly decrease.

\subsection{Design Antenna with Printed Figure U-Shaped}

The Effect of Print Figure U Shape on Power Reflection Coefficient and Resonance Frequency

The simulated plot of varied reflections coefficient $(\mathrm{S} 11<-10 \mathrm{~dB})$ and resonant frequencies that obtained by effect various lengths D-L from $28 \mathrm{~mm}$ until $38 \mathrm{~mm}$ is shown in Figure 8(a).

Figure $8(b)$ shows the general effect of the variable parameter (D-L), with the increase in the (D-L), there is a significant change in the resonant frequency (FR-2) and curve shift towards lower resonant frequencies, while there's no change in the resonant frequency (FR-1). 


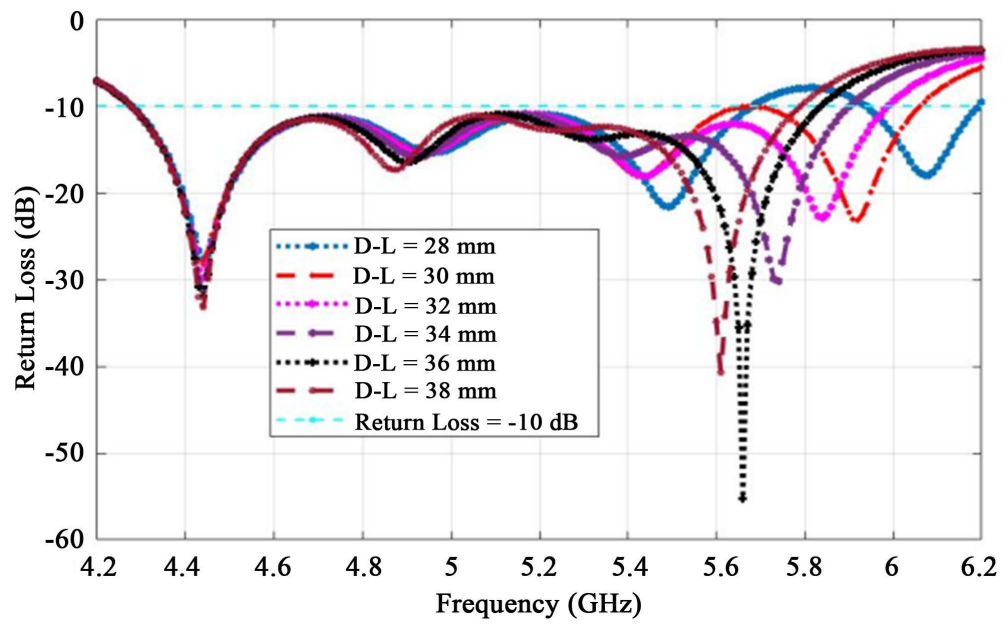

(a)

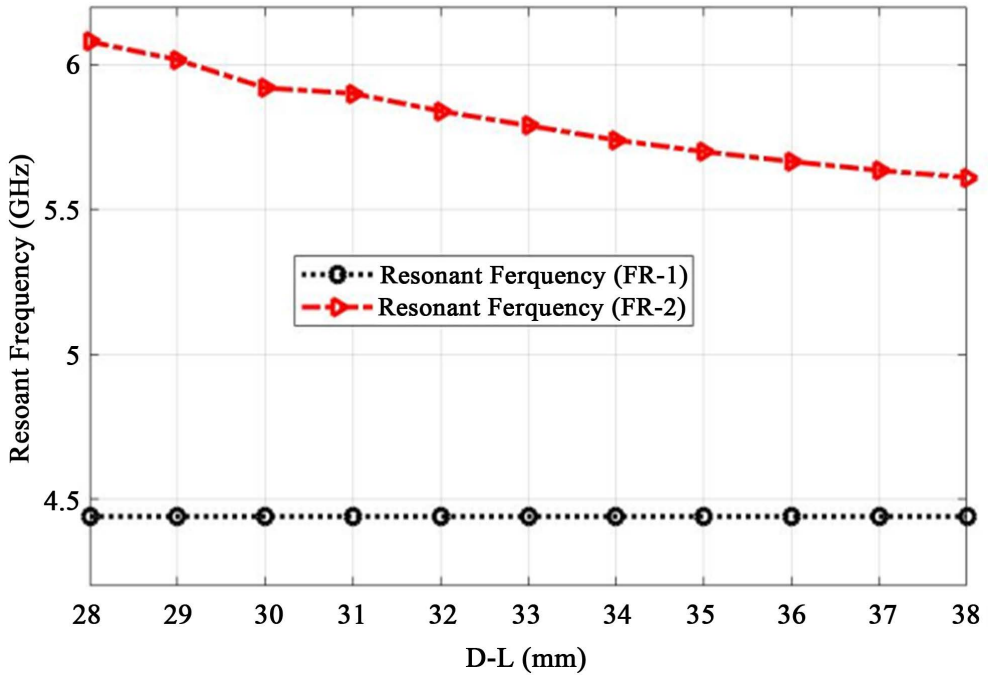

(b)

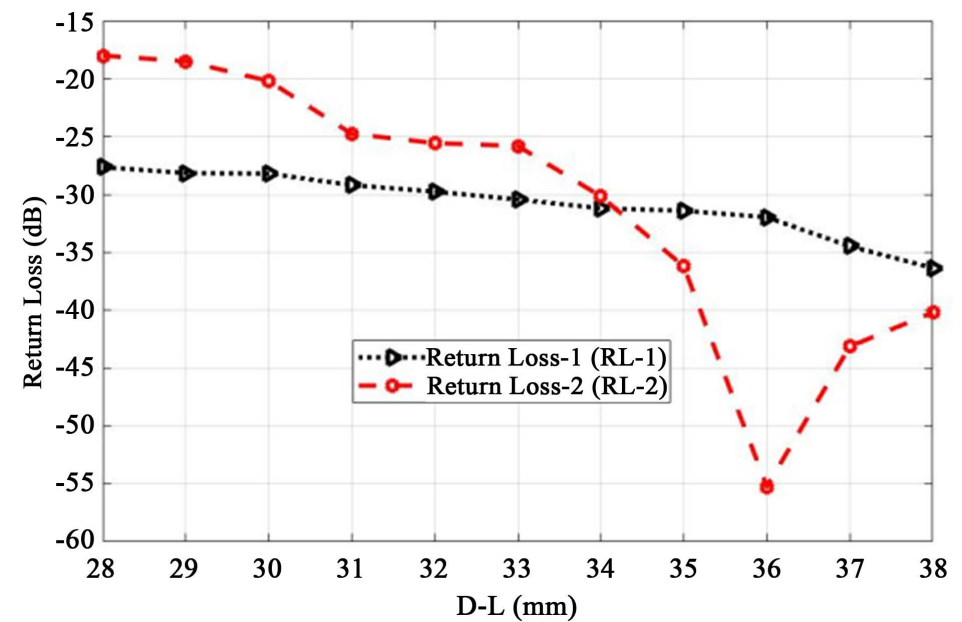

(c)

Figure 8. (a) Power reflection coefficient (S11) and resonance frequency different values of (D-L); (b) Resonance frequency for different values of (D-L); (c) Power reflection coefficient (S11) for different (D-L). 
AS the D-L move towards a higher increased there more amount to the fringing effects occurred, and this leads to a better return loss (RL-1), whereas return loss (RL-2) has a maximum amount at D-L is equal $36 \mathrm{~mm}$. After that, it turns into inverse direction as shown in Figure 8(c).

\subsection{The Dissimilarity between the Figures $E$ and $U$}

\subsubsection{The Dissimilarity of Resonance Frequencies}

Two resonant frequencies obtained from the conventional patch antenna with the figures $\mathrm{E}$ and $\mathrm{U}$. The results very similar of the simulation of two different designs as shown in Figure 9(a) and Figure 9(b) were obtained.

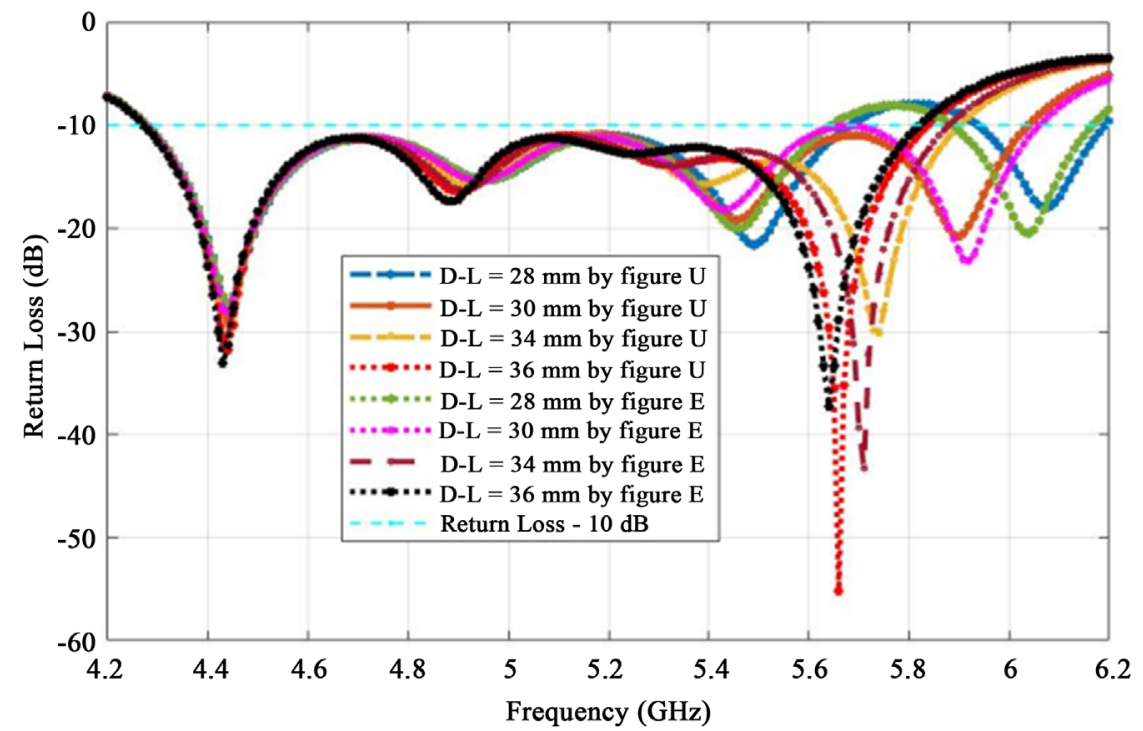

(a)

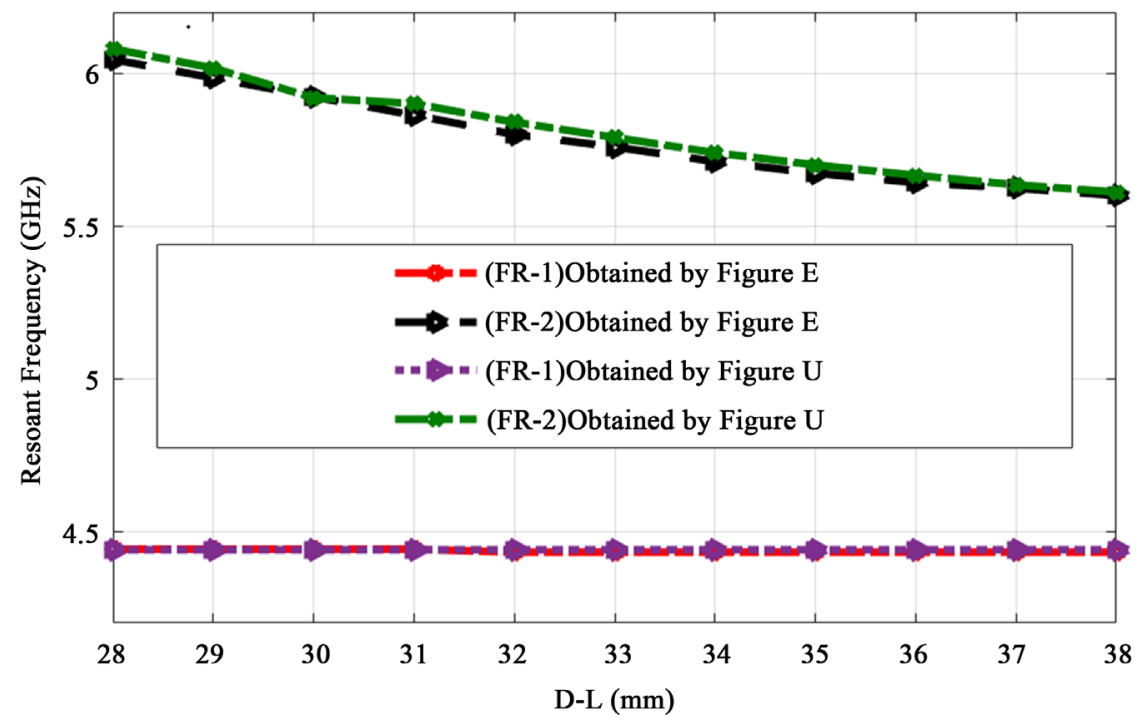

(b)

Figure 9. (a) Dissimilarity between the figures of E-shape and U-shape of reflection coefficient and resonant frequency; (b) Dissimilarity between the figures of E-shape and $\mathrm{U}$-shape of resonant frequencies. 


\subsubsection{The Dissimilarity of Return Losses}

The results of return loss (RL-1) very similar of the simulation of two different designs as shown in Figure 9(a) and Figure 10 were obtained, whereas, return loss (RL-2) dissimilar it's irregular, It is a balanced values with activities efficiency by a specified way of the current path that pass through the patch antenna.

\subsubsection{The Dissimilarity of Bandwidths}

Two bandwidths obtained from the conventional patch antenna with the figures $\mathrm{E}$ and $\mathrm{U}$. The results very similar of the simulation of two different designs as shown in Figure 11 were obtained.

The simulated of bandwidths are $41.03 \%$ and $30.61 \%$ covering the $(4.270$ $6.091 \mathrm{GHz}$ ) obtained by figure-E, whereas the simulated bandwidths are $40.18 \%$ and $30.12 \%$ covering the $(4.277-6.061 \mathrm{GHz})$ obtained by figure-U, as shown in Figure 12, Figure 13 and Table 3.

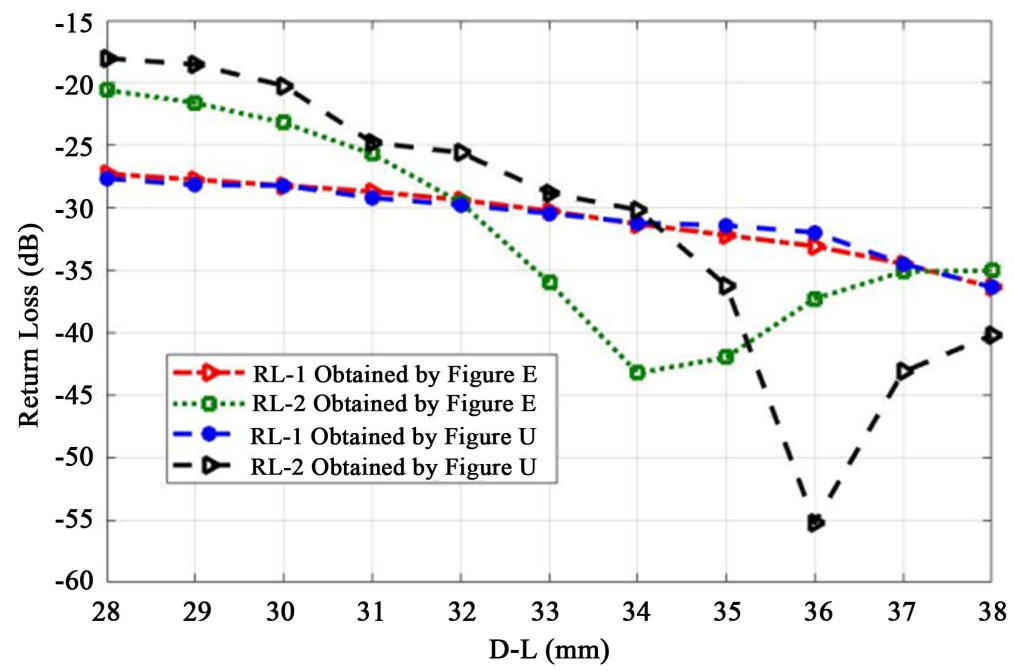

Figure 10. Dissimilarity between the figures of E-shape and U-shape of return losses.

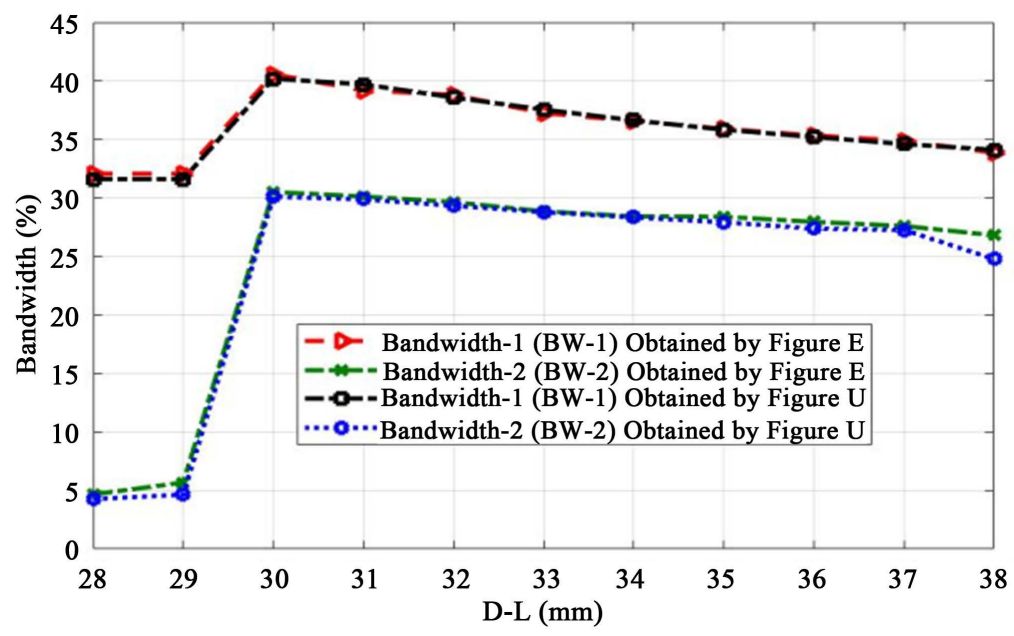

Figure 11. Dissimilarity between the figures of E-shape and U-shape of Bandwidths. 


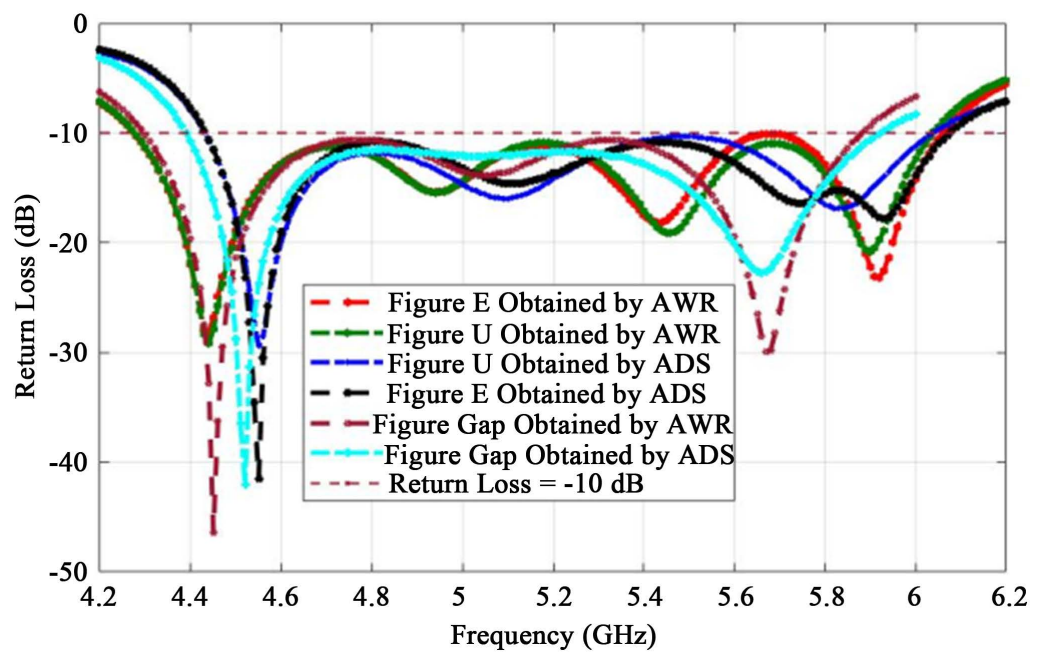

Figure 12. Variation reflection coefficient and resonant Frequency under the Foam Gap, E-Figure, and U-Figure influences.

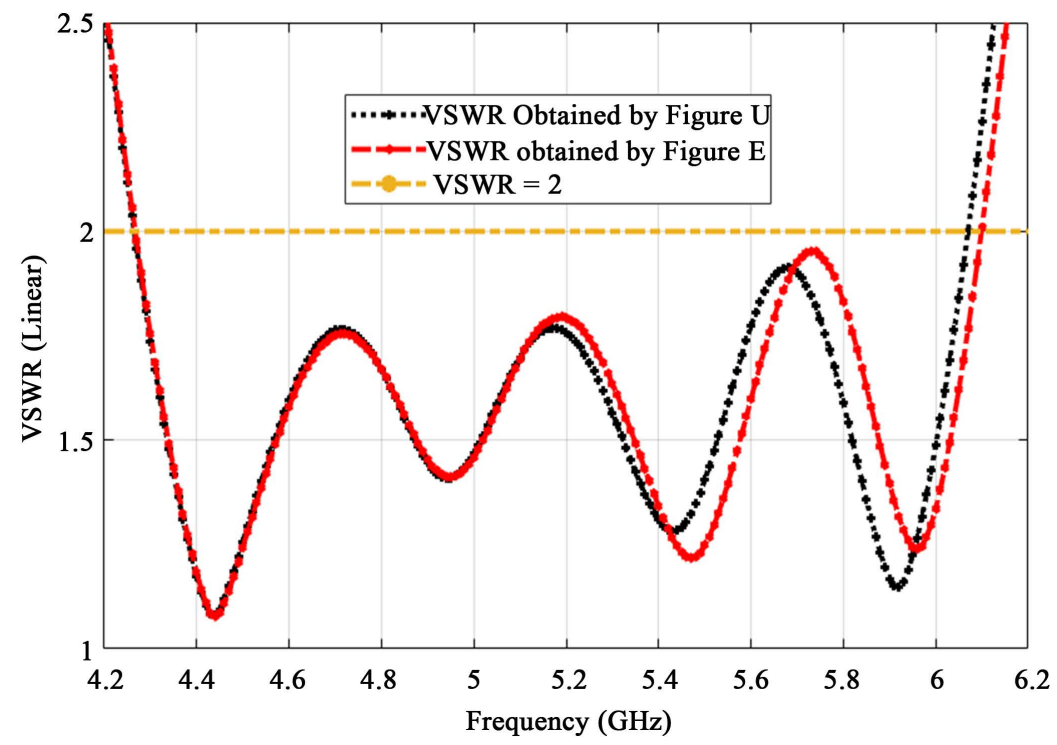

Figure 13. Variation VSWR and resonant frequency under the Foam Gap, E-Figure, and U-Figure influences.

Table 3. Summary of simulated results of final design an antenna.

\begin{tabular}{cccc}
\hline Parameters & Figure E & Figure U & Foam \\
\hline Resonant Frequencies in GHz & $4.442-5.833$ & $4.440-5.920$ & $4.425-5.632$ \\
Return Loss in dB & $28.47-21.65$ & $28.21-23.06$ & $40.64-35.37$ \\
Bandwidth in \% & $41.03-30.61$ & $40.18-30.10$ & $36.17-28.43$ \\
Bandwidth in GHz & 1.821 & 1.784 & 1.628 \\
Gain in dBi & $8.789-9.966$ & $8.635-9.889$ & $7.922-8.710$ \\
Directivity in dBi & $9.782-10.262$ & $9.623-10.113$ & $8.267-10.084$ \\
VSWR & $1.081-1.155$ & $1.080-1.149$ & $1.078-1.094$ \\
\hline
\end{tabular}




\section{Conclusion}

In this paper, the antenna design has been simulated successfully to operate at specified frequencies through specified new technique simulated by different algorithms with perfect agreement of results, whereas, the specified frequencies are $4.440 \mathrm{GHz}$ and $5.5 .833 \mathrm{GHz}$. The simulation results demonstrate clearly and definitely that new technique can be used to optimize bandwidth and gain for specified antenna. The bandwidths have been obtained $41.03 \%$ and $30.61 \%$ for specified frequencies respectively to operate in wireless communications application at Wi-Fi band. The designed antenna has power reflection coefficient (S11) of $-28.62 \mathrm{~dB}$ and $-23.41 \mathrm{~dB}$ for specified frequencies respectively. The designed broad band antenna has a VSWR value of 1.086 and 1.248. The value of the directivity is $9.782 \mathrm{dBi}$ and $10.262 \mathrm{dBi}$ and the gain magnitude is $8.789 \mathrm{dBi}$ and $9.966 \mathrm{dBi}$.

\section{Conflicts of Interest}

The authors declare no conflicts of interest regarding the publication of this paper.

\section{References}

[1] Balanis, C.A. (1997) Antenna Theory, Analysis and Design. John Wiley \& Sons, New York.

[2] Xiong, J., Ying, Z. and He, S. (2008) A Broadband E-Shaped Patch Antenna of Compact Size and Low Profile. IEEE Antennas and Propagation Society International Symposium, San Diego, 5-11 July 2008, 1-4.

[3] Ali, J.K. (2011) A New Dual Band E-Shaped Slot Antenna Design for Wireless Applications. Progress in Electromagnetics Research Symposium, Suzhou, 12-16 September 2011, 12-16.

[4] Kumar, G. and Ray, K.P. (2003) Broadband Microstrip Antennas. Artech House, Norwood, MA.

[5] Chen, W. and Lee, K.F. (1993) Input Impedance of Coaxially Fed Rectangular Microstrip Antenna on Electrically Thick Substrate. Microwave and Optical Technology Letters, 6, 387-390. https://doi.org/10.1002/mop.4650060616

[6] Bhattacharayya, A.K. (1990) Characteristics of Space and Surface-Waves in a Multilayered Structure. IEEE Transactions on Antennas and Propagation, 38, 1231-1238. https://doi.org/10.1109/8.56959

[7] Almuzwghi, A.E. and Brian, L. (2019) Broad Band Microstrip Patch Antenna Using Foam Gap Substrate for Wi-Fi Band. International Journal of Engineering Research and Applications, 9, 48-52.

[8] Radavaram, S. and Pour, M. (2019) Wideband Radiation Reconfigurable Microstrip Patch Antenna Loaded with Two Inverted U-Slots. IEEE Transactions on Antennas and Propagation, 67, 1501-1508. https://doi.org/10.1109/TAP.2018.2885433

[9] Kara, M. (1998) Design Considerations for Rectangular Microstrip Antenna Elements with Various Substrate Thicknesses. Microwave and Optical Technology Letters, 19, 111-121. https://doi.org/10.1002/(SICI)1098-2760(19981005)19:2<111::AID-MOP8>3.0.CO;2 $\underline{-\mathrm{J}}$ 
[10] Tong, K.F., Luk, K.M., Lee, K.F. and Lee, R.Q. (1993) A Broad-Band U-Slot Rectangular Patch Antenna on a Microwave Substrate. IEEE Transactions on Antennas and Propagation, 48, 954-960. https://doi.org/10.1109/8.865229

[11] Ayoub, A.F.A. (2003) Analysis of Rectangular Microstrip Antennas with Air Substrates. Journal of Electromagnetic Waves and Applications, 17, 1755-1756. https://doi.org/10.1163/156939303322760335

[12] Luk, K.M., Mak, C.L., Chow, Y.L. and Lee, K.F. (1998) Broadband Microstrip Patch Antenna. Electronics Letters, 34, 1442-1443. https://doi.org/10.1049/el:19981009

[13] Anguera, J., Puente, C., Borja, C., Delbene, N. and Soler, J. (2003) Dual Frequency Broadband Stacked Microstrip Patch Antenna. IEEE Antennas and Wireless Propagation Letters, 2, 36-39. https://doi.org/10.1109/LAWP.2003.811325

[14] Huynh, T. and Lee, K.F. (1995) Single-Layer Single-Patch Wideband Microstrip Antenna. Electronics Letters, 31, 1310-1312. https://doi.org/10.1049/el:19950950

[15] Tong, K.F., Luk, K.M., Lee, K.F. and Lee, R.Q. (2000) A Broad-Band U-Slot Rectangular Patch Antenna on a Microwave Substrate. IEEE Transactions on Antennas and Propagation, 48, 954-960. https://doi.org/10.1109/8.865229

[16] Lee, K.F., Luk, K.M., Tong, K.F., Yung, Y.L. and Huynh, T. (1996) Experimental Study of a Two-Element Array of U-Slot Patches. Electronics Letters, 32, 418-420. https://doi.org/10.1049/el:19960290

[17] Lee, K.F., Luk, K.M., Tong, K.F., Shum, S.M., Huynh, T. and Lee, R.Q. (1997) Experimental and Simulation Studies of Coaxially Fed U-Slot Rectangular Patch Antenna. IEE Proceedings-Microwaves, Antennas and Propagation, 144, 354. https://doi.org/10.1049/ip-map:19971334

[18] Tong, K.F. and Wong, T.P. (2007) Circularly Polarized U-Slot Antenna. IEEE Transactions on Antennas and Propagation, 55, 2382-2385. https://doi.org/10.1109/TAP.2007.901930

[19] Kumar, G. and Ray, K.P. (2003) Broadband Microstrip Antennas. Artech House, Norwood, MA.

[20] Deshmukh, A.A. and Kumar, G. (2005) Compact Broadband E-Shaped Microstrip Antennas. Electronics Letters, 4, 989-990. https://doi.org/10.1049/el:20051789

[21] Kharade, A.R. and Patil, V.P. (2012) Enhancement of Gain of Rectangular Micro Strip Antenna Using Multilayer Multi Dielectric Structure. IOSR Journal of Electronics and Communication Engineering, 2, 35-40. https://doi.org/10.9790/2834-0263540

[22] Ali, M.T., Jaafar, H., Subahir, S. and Yusof, A.L. (2012) Gain Enhancement of Air Substrates at $5.8 \mathrm{GHz}$ for Microstrip Antenna Array. 2012 Asia-Pacific Symposium on Electromagnetic Compatibility, Singapore, 21-24 May 2012, 477-480. https://doi.org/10.1109/APEMC.2012.6237872

[23] Yan, N., Ma, K. and Zhang, H. (2018) A Novel Substrate-Integrated Suspended Line Stacked-Patch Antenna Array for WLAN. IEEE Transactions on Antennas and Propagation, 66, 3491-3499. https://doi.org/10.1109/TAP.2018.2826719 